\title{
Phenotypic and genotypic analysis of biofilm production by Pseudomonas aeruginosa isolates from infection and colonization samples
}

\author{
Rodrigo Lira Rodrigues ${ }^{[1]}$, Jailton Lobo da Costa Lima ${ }^{[1]}$, \\ Kêsia Xisto da Fonseca Ribeiro de Sena ${ }^{[2]}$ and Maria Amélia Vieira Maciel[1]
}

[1]. Universidade Federal de Pernambuco, Centro de Ciências Médicas, Coordenação de Área Medicina Tropical, Recife, PE, Brasil.

[2]. Universidade Federal de Pernambuco, Centro de Biociências, Departamento de Antibióticos, Recife, PE, Brasil.

\begin{abstract}
Introduction: Pseudomonas aeruginosa is an opportunistic pathogen associated with healthcare-related infections, affecting mainly patients with underlying diseases and immunosuppression. This microorganism has several virulence mechanisms that favour its pathogenesis, including the production of biofilm. This study aimed to analyze the phenotypic production of biofilms, the occurrence of quorum sensing (QS) genes, and the clonal profile of clinical isolates of $P$. aeruginosa from colonized/infected patients in a tertiary hospital in Recife-PE. Methods: We obtained 21 isolates that were classified as infection isolates (II), and 10 colonization isolates (CI). The phenotypic analysis for biofilm production was performed quantitatively. The QS genes were detected by specific PCRs, and the clonal profile was assessed using ERIC-PCR. Results: Of the 31 isolates, 58.1\% (18/31) were biofilm producers, of which $70 \%(7 / 10)$ were CI and classified as weakly adherent; $52.4 \%(11 / 21)$ of the II produced biofilms, and were classified as weak $(38.1 \%,(8 / 21))$, moderate $(9.5 \%,(2 / 21))$, and strongly adherent $(4.8 \%,(1 / 21))$. All isolates harbored the QS genes analyzed. In the clonal analysis, 26 distinct genetic profiles were identified, highlighting the presence of a clone in four samples, i.e., one infection isolate, and 3 colonization isolates. Conclusions: The detection of biofilm formation is important in P. aeruginosa in addition to the identification of colonization and infection isolates, especially from complex environments such as ICUs. Further, we define a strategy for monitoring and analyzing $P$. aeruginosa strains that can potentially cause infections in hospitalized patients.
\end{abstract}

Keywords: Biofilm. Colonization. Pseudomonas aeruginosa. Quorum sensing. Surveillance.

\section{INTRODUCTION}

Pseudomonas aeruginosa is a bacillus species found in soil, water, and the digestive tract of some animals. It is grown in the laboratory on cetrimide agar which is used for the selective isolation of bacteria, and it enables the observation of the large, mucoid, greenish colonies that have a characteristically sweetish odor and fluoresce in the presence of ultraviolet light due to the production of pyoverdin. Additionally, the colonies have been shown to withstand temperatures of $4-42^{\circ} \mathrm{C}^{1,2}$.

The $P$. aeruginosa bacterium is an opportunistic pathogen that colonizes immunosuppressed individuals that have underlying

\footnotetext{
Corresponding author: Msc. Jailton Lobo da Costa Lima.

e-mail: jailtonlobo@hotmail.com

(D) https://orcid.org/0000-0002-5500-1129

Received 26 June 2020

Accepted 11 August 2020
}

diseases, and patients who are admitted to the intensive care units (ICU) in hospitals ${ }^{2,3,4}$. Due to its virulence, the pathogen can colonize second and third-degree burns in individuals, patients on mechanical ventilation, biomaterials (such as catheters, prostheses, and contact lenses), the urinary tract, and the cornea ${ }^{5,6}$.

$P$. aeruginosa is an important etiological agent associated with healthcare-related infections and it has been shown to increase the rate of mortality and morbidity in patients. It can potentially become multidrug-resistant due to its ability to acquire different antimicrobial resistance mechanisms ${ }^{3,6,7,8,9}$.

The pathogen shows the ability to produce biofilms, which are an important factor for virulence and bacterial resistance, and can have a strong impact on the health of the host. The dense polysaccharide matrix of the biofilm contributes to the persistence of infection, the ineffective action of antimicrobials, and the escape from the phagocytic actions of the cells of the immune system of the host, these effects result in chronic pathology ${ }^{5,6,10,11}$. Biofilms enable the 
survival of bacteria on abiotic surfaces and facilitate pathogen permanence and its dissemination between hospital beds ${ }^{8,12,13}$. An estimated $80 \%$ of $P$. aeruginosa infections are associated with biofilm production, such as in patients undergoing mechanical ventilation, or those having cystic fibrosis or burns ${ }^{3,5,6,14}$.

Like mammalian cells, bacteria respond to molecules and interact with the receptors of other microorganisms to communicate ${ }^{1,15}$. This biochemical interaction is necessary for the formation of biofilms and the production of other virulence factors. These molecules, which are self-inducting, can be produced and secreted by the bacterial community itself. At high concentrations, these molecules stimulate biofilm production due to the transcription of specific genes. This complex communication mechanism is called quorum sensing $(\mathrm{QS})^{13,16,17}$. QS enables $P$. aeruginosa to respond to the self-inducting molecules called acyl-homoserine lactones (AHLs) that target the Las and Rhl genes.

Further, the lasI, rhlI, and pqsA genes are responsible for the biosynthesis of the signaling molecules $\mathrm{N}$-(3-oxododecanoyl)L-homoserine lactone (OdDHL), N-Butyrylhomoserine lactone (BHL), and the Pseudomonas quinolone signal (PQS), respectively. The corresponding receptors for the signaling molecules are LasR, RhlR, and PqsR, respectively, which are involved in the regulation of bacterial virulence and biofilm formation ${ }^{17,18,19,20}$.

In this study, we aimed at analyzing $P$. aeruginosa isolates from colonized and infected patients to verify biofilm production phenotypically, search for QS genes (lasI, lasR, rhlI, and rhlR), and undertake an analysis of the clonal profile of the isolates.

\section{METHODS}

\section{Bacterial isolates and their sources}

The bacterial isolates analyzed in this study were obtained from patients admitted to a public hospital in Recife, Pernambuco, Brazil. The samples were provided by the bacteriological division of the hospital and were collected between 2018-2019. This study was approved by the Ethics Committee on Research of the Universidade Federal de Pernambuco, Brazil (Ref. No. 0490.0.172.000-11). A total of 31 P. aeruginosa isolates were obtained from patients, of which 21 were infection isolates (II), and ten were colonization isolates $(\mathrm{CI})$, based on the criteria adopted by the microbiology laboratory of the hospital. The isolates were stored at $-20^{\circ} \mathrm{C}$ at the Bacteriology and Molecular Biology Laboratory, Universidade Federal de Pernambuco. The frozen isolates were reactivated in Brain Heart Infusion (BHI) medium, incubated for $24 \mathrm{~h}$ at $37^{\circ} \mathrm{C}$, and were subsequently seeded in cetrimide agar and incubated for an additional $24 \mathrm{~h}$ at $37^{\circ} \mathrm{C}$. These isolates represented diverse clinical and surveillance samples (Table 1).

\section{Biofilm production test}

P. aeruginosa isolates were grown in BHI broth for $24 \mathrm{~h}$ at $37^{\circ} \mathrm{C}$. Next, $200 \mu \mathrm{L}$ of the bacterial suspension was applied to flat bottomed 96-well polystyrene plates in triplicate for microtitration. BHI broth was used as a negative control, and the PA01 strain of $P$. aeruginosa was used as a positive control (CP) to test for biofilm production. The plates were incubated at $37^{\circ} \mathrm{C}$ for $24 \mathrm{~h}$, and subsequently, the bacterial suspensions were removed, and each well was washed three times with $250 \mu \mathrm{L}$ of saline $(0.9 \%$
$\mathrm{NaCl}$ (Dinâmica)). The bacterial samples were fixed using 200 $\mu \mathrm{L}$ of methanol (Química Moderna) for $15 \mathrm{~min}$. After methanol removal, the plates were left to dry at room temperature and were stained with $200 \mu \mathrm{L}$ of crystal violet (Newprov) solution for $5 \mathrm{~min}$.

Next, the plates were washed under running water and dried at room temperature. The absorbance at $\mathrm{A}_{570}$ was measured using an ELISA plate reader (BioRad, model 550), and the samples were classified as described by Stepanovic and collaborators $(2000)^{11}$. The optical density for each isolate (ODi) was obtained by averaging the three wells, and this value was compared with the optical density of the negative control (ODc). The isolates were classified into four categories based on the average of the ODi obtained relative to the ODc. The classification criteria for each category included cells that were not adherent $(\mathrm{ODi} \leq \mathrm{ODc})$; weakly adherent $(+)(\mathrm{ODc}<\mathrm{ODi}$ $\leq 2 \times \mathrm{ODc})$; moderately adherent $(++)(2 \times \mathrm{ODc}<\mathrm{ODi} \leq 4 \times \mathrm{ODc})$; and strongly adherent $(4 \times \mathrm{ODc}<\mathrm{ODi})$.

\section{Detection of genes related to biofilm production}

Total DNA extraction was performed using the Brazol kit (LGCBiotecnologia), as per the protocol provided by the manufacturer, and the DNA was quantified via spectrophotometry (Ultraspec 3000; Pharmacia Biotech). A simple quantification was performed using the absorbance at $260 \mathrm{~nm}$ and an assessment of purity performed using the 260/280 ratio. The genes associated with QS i.e., lasI, lasR, $r h l l$, and $r h l R^{14,15}$ were amplified via PCR using the primers listed in Table 2. The parameters used for the PCR were 30 cycles of denaturation at $94^{\circ} \mathrm{C}$ for $1 \mathrm{~min}$, annealing at $52^{\circ} \mathrm{C}$ for $1 \mathrm{~min}$, and an extension step at $72^{\circ} \mathrm{C}$ for $1.5 \mathrm{~min}$. The Blue Green (LGC Biotecnologia, São Paulo) stained PCR products were run on a $2 \%$ agarose gel using electrophoresis and were visualized under UV light.

\section{Molecular typing of the isolates}

The 31 isolates were analyzed via molecular typing by using the enterobacterial repetitive intergenic consensus-based PCR (ERIC-PCR) technique to determine the clonal profile of the strains. The PCR was performed in a total volume of 25 $\mu \mathrm{L}$ per tube containing $100 \mathrm{ng}$ of DNA, 10 pmol of primers (ERIC-1 [5'-ATGTAAGCTCCTGGGGATTCAC-3']; ERIC-2 [5'AAGTAAGTGACTGGGGTGAGG-3']), 1x buffer, $200 \mu \mathrm{M}$ deoxyribonucleotide triphosphate (Ludwig Biotec), $1.5 \mathrm{mM}$ of $\mathrm{MgCl}_{2}$ and $1 \mathrm{U}$ of DNA Taq Polymerase (Promega). The amplification parameters for ERIC-PCR were initial denaturation at $95^{\circ} \mathrm{C}$ for $3 \mathrm{~min}$, followed by 30 at $92^{\circ} \mathrm{C}$ for $1 \mathrm{~min}$, annealing at $36^{\circ} \mathrm{C}$ for $1 \mathrm{~min}$, an extension step at $72^{\circ} \mathrm{C}$ for $8 \mathrm{~min}$ and a final extension at $72^{\circ} \mathrm{C}$ for $16 \mathrm{~min}$. The PCR products were stained with Blue Green (LGC Biotecnologia, São Paulo), and analyzed by agarose gel electrophoresis using a 1.5 $\%$ agarose gel. The DNA bands were visualized under UV light and photodocumented (Kasvi) for clonal analysis ${ }^{21}$.

\section{RESULTS}

\section{Origin of isolates}

In the II samples, the highest prevalence of bacterial isolates was detected in blood $33.3 \%$ (7/21); $23.8 \%(5 / 21)$ of the tracheal secretion and urine samples showed the presence of bacteria. In the CI samples, $90 \%(9 / 10)$ tested positive, and these were obtained from a rectal swab culture (Table 1). 
TABLE 1: Description of $P$. aeruginosa isolates based on the clinical/surveillance sample type.

\begin{tabular}{|c|c|c|c|c|}
\hline Identification & Hospital Sector & Source & Classification & Adhesion Profile of Biofilm \\
\hline P01 & ICU & Tracheal secretion & Infection & Non-adherent \\
\hline P02 & ICU & Rectal swab & Colonization & Weakly adherent \\
\hline P03 & $\mathrm{ICU}$ & Urine & Infection & Non-adherent \\
\hline P04 & ICU & Tracheal secretion & Infection & Weakly adherent \\
\hline P05 & ICU & Tracheal secretion & Infection & Weakly adherent \\
\hline P06 & $\mathrm{ICU}$ & Rectal swab & Colonization & Weakly adherent \\
\hline P07 & UCO & Tracheal secretion & Infection & Moderately adherent \\
\hline P08 & UCO & Tracheal secretion & Infection & Moderately adherent \\
\hline P09 & $\mathrm{ICU}$ & Catheter tip & Infection & Weakly adherent \\
\hline P12 & $\mathrm{CL}$ & Nasal swab & Colonization & Weakly adherent \\
\hline P15 & $\mathrm{CL}$ & Blood & Infection & Weakly adherent \\
\hline P17 & UCO & Rectal swab & Colonization & Non-adherent \\
\hline P18 & SC & Urine & Infection & Non-adherent \\
\hline P22 & ER & Urine & Infection & Weakly adherent \\
\hline P23 & $\mathrm{CL}$ & Urine & Infection & Strongly adherent \\
\hline P24 & $\mathrm{SC}$ & Catheter tip & Infection & Non-adherent \\
\hline P27 & UCO & Rectal swab & Colonization & Non-adherent \\
\hline P28 & CARDIO & Urine & Infection & Weakly adherent \\
\hline P29 & ICU & Blood & Infection & Non-adherent \\
\hline P31 & CARDIO & Blood & Infection & Non-adherent \\
\hline P32 & CARDIO & Blood & Infection & Non-adherent \\
\hline P42 & ICU & Blood & Infection & Non-adherent \\
\hline P44 & UCO & Rectal swab & Colonization & Weakly adherent \\
\hline P46 & $\mathrm{ICU}$ & Catheter tip & Infection & Non-adherent \\
\hline P51 & ICU & Rectal swab & Colonization & Weakly adherent \\
\hline P59 & UCO & Blood & Infection & Weakly adherent \\
\hline P63 & ICU & Rectal swab & Colonization & Weakly adherent \\
\hline P66 & UCO & Rectal swab & Colonization & Weakly adherent \\
\hline P67 & $\mathrm{ICU}$ & Blood & Infection & Weakly adherent \\
\hline P70 & UCO & Rectal swab & Colonization & Non-adherent \\
\hline P79 & ICU & Catheter tip & Infection & Non-adherent \\
\hline
\end{tabular}

ICU: Intensive Care Unit; UCO: Coronary Unit; CL: Clinic; SC: Surgical Clinic; CARDIO: Cardiology Clinic; ER: Emergency Room. 
TABLE 2: Sequences of primers used for the detection of quorum-sensing genes.

\begin{tabular}{|c|c|c|}
\hline Genes & Primers & Base pairs (bp) \\
\hline IlasI & $\begin{array}{l}\text { 5'-CGTGCTCAAGTGTTCAAGG-3' } \\
\text { 5'-TACAGTCGGAAAAGCCCAG-3' }\end{array}$ & 295 \\
\hline IlasR & $\begin{array}{l}\text { 5'-AAGTGGAAAATTGGAGTGGAG-3' } \\
\text { 5'-GTAGTTGCCGACGACGATGAAG-3' }\end{array}$ & 130 \\
\hline rrhll & $\begin{array}{l}\text { 5'-TTCATCCTCCTTTAGTCTTCCC-3' } \\
\text { 5'-TTCCAGCGATTCAGAGAGC-3' }\end{array}$ & 155 \\
\hline$r r h I R$ & $\begin{array}{l}\text { 5'-TGCATTTTATCGATCAGGGC-3' } \\
\text { 5'-CACTTCCTTTTCCAGGACG-3' }\end{array}$ & 133 \\
\hline
\end{tabular}

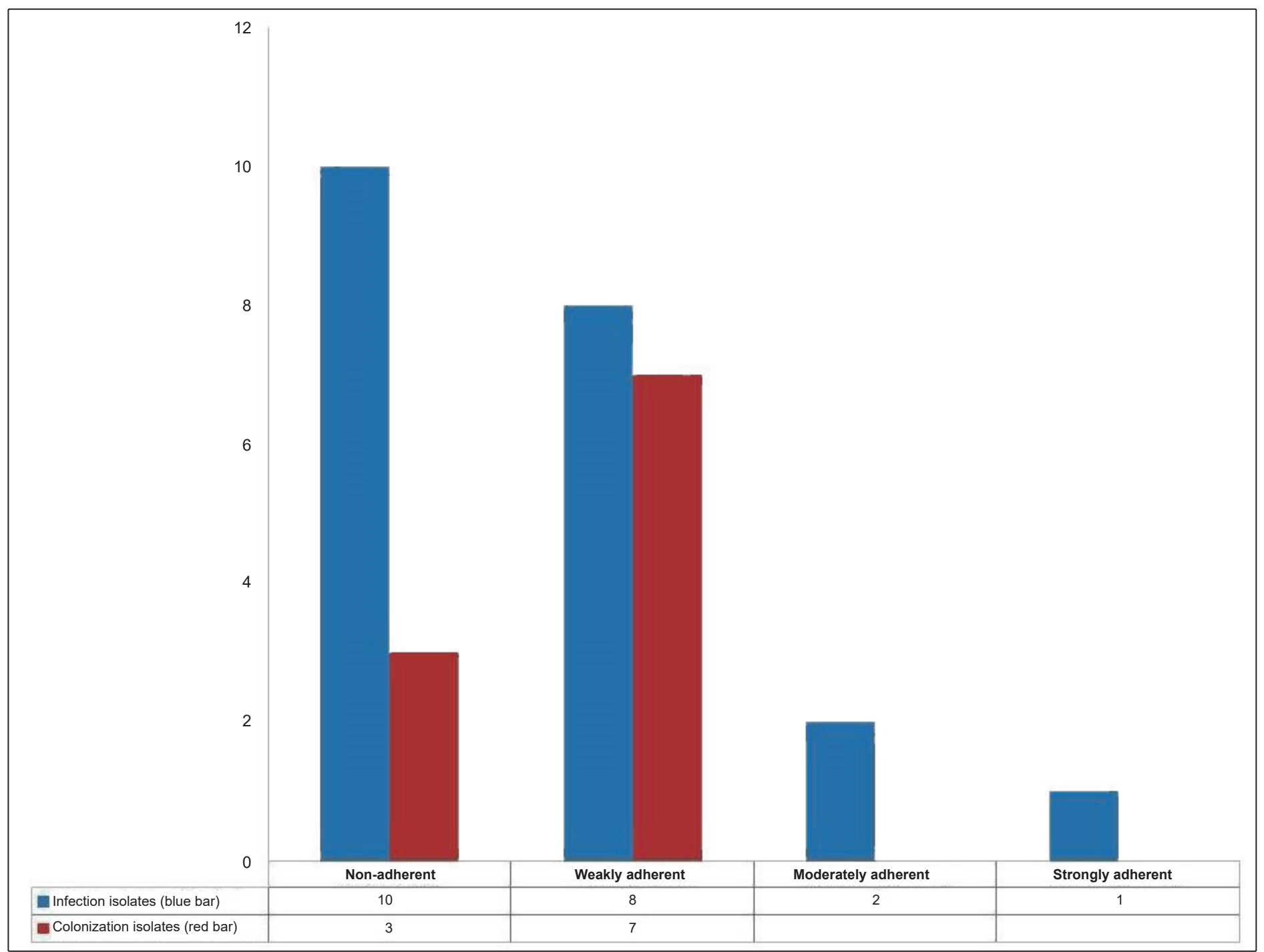

FIGURE 1: The profile of biofilm production by the infection and colonization isolates. 


\section{Phenotypic analysis of the biofilm production}

Of the 31 isolates studied, $58.1 \%(18 / 31)$ were biofilm producers. After staining and analysis using the spectrophotometer, the isolates were classified as described in the work by Stepanovic et $a l^{11}$. In the CI samples, $70 \%$ (7/10) showed a weakly adherent profile. In the II samples, $52.4 \%$ (11/21) isolates produced biofilms, and these were classified as weak $(38.1 \% ;(8 / 21))$, moderate $(9.5 \% ;(2 / 21))$, and strongly adherent $(4.8 \% ;(1 / 21))$ (Figure 1).

\section{Quorum-sensing gene analysis}

All 31 isolates had the four QS genes studied (lasI, lasR, rhlI, and $r h l R$ ).

\section{Clonal profiles of isolates}

We performed a clonal profile analysis (Figure 2) and identified 26 distinct genetic profiles, that showed high genetic variability between the isolates. Additionally, it is possible to see the occurrence of three clones, one of which composed of four isolates PA31 (infection), PA44, PA63, and PA66 (all of which are colonization isolates). These results indicate that this clone was disseminated between colonized and infected patients.

\section{DISCUSSION}

The II analyzed in this study were obtained from different infection sites, although samples of blood, tracheal secretion, and urine were the most prevalent sources of $P$. aeruginosa, and this data was similar to that from Goncalvez et al., $(2017)^{22}$. The authors described bacteremia without a defined focus of infection as the most frequent source and the respiratory tract as a second site of infection. In a study by Lima et al. (2018) ${ }^{1}$, the authors showed that there was a higher prevalence of infection in samples from tracheal secretions, followed by blood samples. Further, Brusselaers et al. (2011) described the Intensive Care Unit (ICU) of hospitals as showing a high frequency of infections ${ }^{23}$, and $P$. aeruginosa was significantly responsible for a wide range of infections in critically ill patients that were acquired in the ICU.

We used a quantitative phenotypic test considered to be a gold standard to detect biofilm production by clinical isolates of $P$. aeruginosa. Moreover, different studies that used the same technique to analyze biofilm production by $P$. aeruginosa obtained percentages for biofilm production ranging from $73.7 \%$ to 98.6 $\%$ in the isolates analyzed ${ }^{1,3,6,9,10,24}$, that were higher than those described in this study.

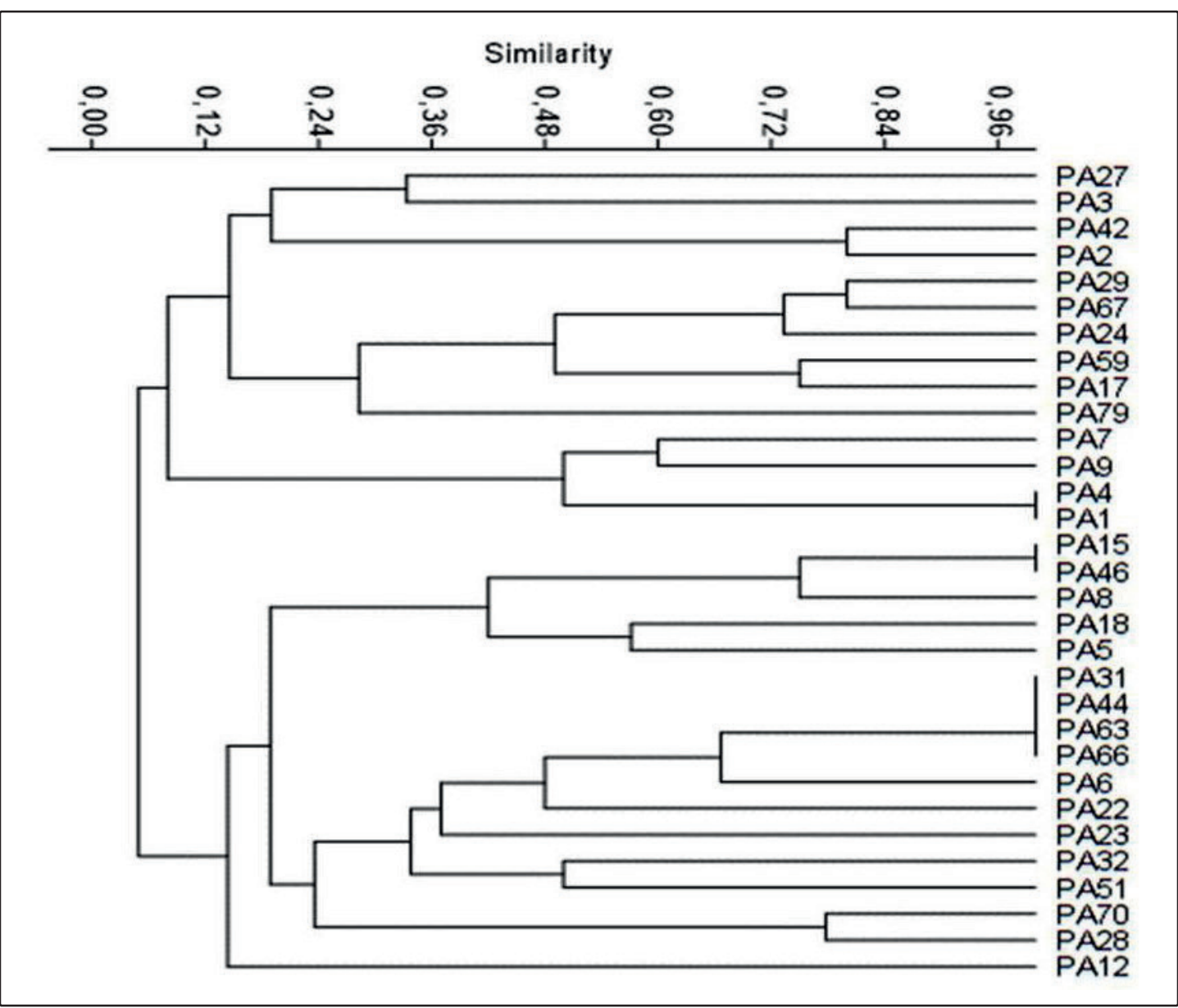

FIGURE 2: The dendrogram was constructed by analyzing the results of the ERIC-PCR sequences and was generated using the PAST software for 31 clinical isolates of $P$. aeruginosa. 
The adhesion profile of the biofilm showed a distribution variable of the groups that were classified as weak, moderate, to strongly adherent. Similarly, Perez et al. (2013) ${ }^{9}$ obtained biofilm producer isolates in $93.4 \%$ of the samples tested, and these were further classified as weak ( $56 \%$ ), moderate (24.2\%), and strongly adherent (12.2\%). In a study by Lima et al. (2017) ${ }^{10}, 75 \%$ of the isolates were biofilm producers, and the authors classified them as weak (40 $\%)$, moderate (25\%), and strongly adherent (10\%). Additionally, another study by Lima et al. (2018) ${ }^{1}$ showed $77.5 \%$ of the isolates as biofilm producers, of which $42.5 \%$ were weakly adherent, 27.5 $\%$ were moderately adherent, and $7.5 \%$ were strongly adherent. Consequently, these studies showed a predominance of weakly adherent isolates, which corroborates the results of this study.

Biofilm formation is a complex virulence mechanism, which requires gene regulation by different components of the QS system. Changes in the expression of the genes related to the QS network or the presence of mutations can reduce the production of this important bacterial virulence factor ${ }^{1,12,17}$. The detection of the presence of the QS genes associated with the phenotypic analysis of biofilm production can help in the evaluation of their regulation. In this study, the genotypic analysis of 31 isolates showed a $100 \%$ detection rate for all four investigated genes. Perez et al. (2013) ${ }^{9}$ analyzed 91 isolates of $P$. aeruginosa that were found to infect cystic fibrosis and non-cystic fibrosis patients and demonstrated that all four genes were present in the isolates. Lima et al. (2018) ${ }^{1}$ investigated 40 isolates and described a $100 \%$ detection rate for the las $R$, rhll, and $r h l R$ genes, and a 97.5 $\%$ detection rate for the lasI gene. However, these data differ from the results obtained by Karatuna and Yagci $(2010)^{8}$, in which 81.25 $\%, 68.65 \%$, and $62.5 \%$ of the isolates were positive for the lasI and las $R$ genes, the rhlI gene, and the rhlR gene, respectively.

In our study, although all isolates showed the presence of the quorum-sensing genes analyzed, $41.9 \%$ (13/31) of the isolates did not produce biofilms in the quantitative analysis. This may occur due to the non-expression of these genes or because of the presence of mutations in the genes that regulate the QS system, as found in a study by Senturk et al., (2012) $)^{4}$. The authors sequenced the QS genes involved in biofilm production and observed point mutations in the sequences for the lasR, lasI, rhlR, and rhlI genes that prevented their efficient expression. Lima et al., (2018) ${ }^{1}$ identified nine isolates of $P$. aeruginosa that were not biofilm producers. Sequencing of the las $R$ gene showed the occurrence of mutations at position 53 of the LasR protein, which is close to the binding region for its autoinducer, $\mathrm{N}$-(3-oxododecanoyl) homoserine lactone (OdDHL). The authors attributed the non-formation of biofilm by the $P$. aeruginosa isolates to the mutations observed in the lasR gene.

Perez et al., (2013) $)^{9}$ demonstrated that isolates lacking the lasR and lasI genes were unable to form a biofilm, and the results indicate that these genes play an important role in QS and the formation of biofilms. These findings were similar to those of Persyn et al., (2019) ${ }^{25}$ who sequenced the genome of 12 P. aeruginosa isolates obtained from patients with repeated attacks of pneumonia that were associated with mechanical ventilation. The authors observed that isolates with mutations in the genes associated with the QS system had a lower degree of virulence.

The dendrogram in Figure 2 shows the clustering for the 26 distinct genetic profiles of the isolates obtained, and similar results were observed in other studies ${ }^{12,26}$ that evaluated resistance factors in $P$. aeruginos $a$, such as metalo- $\beta$-lactamases, and showed a higher diversity of genetic profiles of $P$. aeruginosa isolates from public hospitals. Additionally, reports from studies in the literature indicate that similar results were obtained using isolates from patients with chronic infections as these individuals are in an environment favorable for the appearance of random mutations. Further, antibiotic therapy promotes the artificial selection of bacteria for greater drug resistance, primarily in cases where $P$. aeruginosa infection is present, as the mucopolysaccharide constituting the biofilm hinders drug diffusion through cell layers ${ }^{1,14,17,26}$.

The analysis of genetic diversity showed the occurrence of a clone composed of four isolates, one of them II and three CI. Johnson et al., (2009 $)^{27}$ performed a prospective study for five years and analyzed the colonization of $P$. aeruginosa in patients admitted to the ICU. The results suggest that dissemination between patients plays an important role in the acquisition of $P$. aeruginosa colonization on the skin and mucous membranes, and this process precedes the infection that occurs later. Gómez-Zorrilla et al, $(2015)^{28}$ performed a prospective observational study and identified that the prior rectal colonization by P. aeruginosa is a key factor for the development of infection. Additionally, another study ${ }^{29}$ showed that health professionals may directly or indirectly be involved in the microorganism spread chain.

Biofilm production in bacterial isolates is recognized as an important factor for persistent infections ${ }^{30}$. The manifold and diverse mechanisms employed by $P$. aeruginos $a$ to survive antibiotic treatment while growing in a biofilm represent an important therapeutic challenge ${ }^{31}$. Additionally, the acquisition of possible resistance genes is also an important factor ${ }^{12}$; however, this was not analyzed in the present study. Therefore, the emphasis on surveillance culture is important in the implementation of the infection control program, as described by Abdalhamid et al. $2016^{32}$ in a study carried out in ICU patients.

\section{CONCLUSIONS}

In this study, we described the biofilm production in infection and colonization isolates of $P$. aeruginosa from patients admitted to a hospital. Additionally, we detected the presence of high genetic diversity between the isolates, including a clone composed of among infection and colonization isolates, indicating that dissemination had occurred in the hospital environment. The results indicate the importance of the detection of biofilms in P. aeruginosa in both colonization and infection isolates, especially from complex environments such as ICUs. The strategy outlined in this study can be used for monitoring and studying strains that can cause infections in hospitalized patients, though the formation of biofilms remains an important therapeutic challenge.

\section{ACKNOWLEDGMENTS}

We thank the Universidade Federal de Pernambuco that provided technical support for the development and implementation of this study.

\section{FINANCIAL SUPPORT}

CAPES - Coordenação de Aperfeiçoamento de Pessoal de Nível Superior and $\mathrm{CNPq}$ - Conselho Nacional de Desenvolvimento Científico e Tecnológico. 


\section{AUTHOR CONTRIBUTIONS}

RLR: Conception and design of the study, acquisition of data, drafting of the manuscript; JLCL: Conception and design of the study, analysis and interpretation of the data, drafting of the manuscript, and final approval of the version to be submitted; KXFRS: Drafting of the manuscript, and final approval of the version to be submitted; MAVM: Conception and design of the study, analysis and interpretation of the data, drafting of the manuscript, and the final approval of the version to be submitted.

\section{CONFLICT OF INTEREST}

The authors declare that there is no conflict of interest.

\section{REFERENCES}

1. Lima JLC, Alves LR, Jacomé PRLA, Neto B, Pacífco J, Maciel MAV, et al. Bioflm production by clinical isolates of Pseudomonas aeruginosa and structural changes in LasR protein of isolates non bioflm-producing. Braz J Infect Dis. 2018;22(2):129-36.

2. López D, Vlamakis H, Kolter R. Biofilms. Cold Spring Harbor Pespectives in Biology. 2010:1-12.

3. Kırmusaoglu S, Yurdugül S, Metin A, Vehid S. The effect of urinary catheters on microbial biofilms and cateter associated urinary tract infections. Urol J. 2017;14(2):3028-34.

4. Senturk S, Ulusoy S, Bosgelmez-Tinaz G, Yagci A. Quorum sensing and virulence of Pseudomonas aeruginosa during urinary tract infections. J Infect Dev Ctries. 2012;6(6):501-7.

5. Asati S, Chaudhary U. Prevalence of biofilm producing aerobic bacterial isolates in burn wound infections at a tertiary care hospital in northern India. Ann of burns and fire disasters. 2017;30(1):39-42.

6. Di Domenico EG, Farulla I, Prignano G, Gallo MT, Vespaziani M, Cavallo I, Sperduti I, et al. Biofilm is a major virulence determinant in bacterial colonization of chronic skin ulcers independently from the multidrug resistant phenotype. Int J Mol Sci. 2017;18(5):1077.

7. Costerton JW, Stewart PS, Greenberg EP. Bacterial biofilms: a common cause of persistent infections. Science. 1999;284(5418):1318-22.

8. Karatuna O, Yagci A. Analysis of quorum sensing-dependent virulence fator production and its relationship with antimicrobial susceptibility in Pseudomonas aeruginosa respiratory isolates. Clin Microbiol Infect. 2010;16(12):1770-5.

9. Perez LRR, Machado ABMP, Barth AL. The Presence of QuorumSensing Genes in Pseudomonas isolates Infecting Cystic Fibrosis and Non-cystic Fibrosis Patients. Curr Microbiol. 2013;66(4):418-20.

10. Lima JLC, Alves LR, Paz JNP, Rabelo MA, Maciel MAV, Morais MMC. Analysis of biofilm production by clinical isolates of Pseudomonas aeruginosa from patients with ventilator-Associated pneumonia. Rev Bras Ter Intensiva. 2017; 29(3):310-6.

11. Stepanovic S, Vukovic D, Dakic I, Savic B, Svabic-Vlahovic M. A modified microtiter-plate test for quantification of staphylococcal biofilm formation. J Microbiol Methods. 2007;115(8):891-9.

12. Jacome PRLA, Alves LR, Cabral AB, Lopes ACS, Maciel MAV. Phenotypic and molecular characterization of antimicrobial resistance and virulence factors in Pseudomonas aeruginosa clinical isolates from Recife, State of Pernambuco. Brazil. Rev Soc Bras Med Trop. 2012;45(6):707-12.

13. Santos IAL, Nogueira JMR., Mendonça FCR. Mecanismos de resistência antimicrobiana em Pseudomonas aeruginosa. Rev Bras Anal Clin. 2016;47(1/2):5-12.

14. Zhu H, Bandara R, Conibear TCR, Thuruthyil SJ, Rice SA, Kjelleberg S, et al. Pseudomonas aeruginosa with lasI quorum-sensing deficiency during corneal infection. Investig Ophthalmol Vis Sci. 2004;45(6):1897-903.
15. Tingpej P, Smith L. Phenotipic characterization of clonal and nonclonal Pseudomonas aeruginosa strains isolated from lungs of adults with cystic fibrosis. J Clin Microbiol. 2007;45(6):1697-704.

16. Cornelis P. Putting an end to the Pseudomonas aeruginosa IQS controversy. Microbiol Open. 2020;9(2):2019-20.

17. Castillo Rivera ML, Hassimotto NMA, Bueris V, Sircili MP, Almeida FA, Pinto UM. Effect of Capsicum Frutescens Extract, Capsaicin, and Luteolin on Quorum Sensing Regulated Phenotypes. J Food Sci. 2019;84(6):1477-86.

18. Diggle SP, Whiteley M. Pseudomonas aeruginosa: opportunistic pathogen and lab rat. Microbiology. 2020;166(1):30-3.

19. Chen T, Xu Y, Xu W, Liao W, Xu C, Zhang X, et al. Hypertonic glucose inhibits growth and attenuates virulence factors of multidrug-resistant Pseudomonas aeruginosa. BMC Microbiology. 2020;20:203.

20. Lee J, Zhang L. The hierarchy quorum sensing network in Pseudomonas aeruginosa. Protein and Cell. 2014;6(1):26-41.

21. Duan H, Chai T, Liu J, Zhang X, Qi C, Gao J, et al. Source identification of airborne Escherichia coli of swine house surroundings using ERICPCR and REP-PCR. Environ Res. 2009;109(5):511-7.

22. Goncalves IR, Dantas RCC, Ferreira ML, Batistão DLF, GontijoFilho PP, Ribas RM. Carbapenem-resistant Pseudomonas aeruginosa: association with virulence genes and biofilm formation. Braz $\mathrm{J}$ Microbiol. 2017;48(2):211-7.

23. Brusselaers N, Vogelaers D, Blot S. The rising problem of antimicrobial resistance in the intensive care unit. Ann Intensive Care. 2011;1(47):1-7.

24. Bahador N, Shoja S, Faridi F. Molecular detection of virulence factors and biofilm formation in Pseudomonas aeruginosa obtained from diffrent clinical specimens in Bandar Abbas. Iran J Microbiol. 2019;11(1):25-30.

25. Persyn E. Rapid genetic and phenotypic cheanges in Pseudomonas aeruginosa clinical strains during ventilator-associated peneumonia. Scientific Reports. 2019;9(1): 1-8.

26. Cavalcanti FLS, Almeida ACS, Vilela MA, Morais MMC, Morais Júnior AM. Changing the epidemiology of carbapenem-resistant Pseudomonas aeruginosa in a Brazilian teaching hospital: the replacement of São Paulo metallo- $\beta$-lactamase-producing isolates. Mem Inst Oswaldo Cruz. 2012;107(3):420-3.

27. Johnson JK, Smith G, Lee MS, Venezia RA, Stine OC, Nataro JP, et al. The role of patient-to-patient transmission in the acquisition of imipenem-resistant Pseudomonas aeruginosa colonization in the intensive care unit. J Infect Dis. 2009;200(6):900-5.

28. Gómez-Zorrilla S, Camoez M, Tubau F, Cañizares R, Periche E, Dominguez MA, et al. Prospective Observational Study of Prior Rectal Colonization Status as a Predictor for Subsequent Development of Pseudomonas aeruginosa Clinical Infections. Antimicrob Agents Chemother. 2015;59(9):5213-9.

29. Zaha DC, Kiss R, Hegeds C, Gesztelyi R, Bombicz M, Muresan M, et al. Recent advances in investigation, prevention, and management of healthcare-associated infections (HAIs): resistant multidrug strain colonization and its risk factors in an intensive care unit of a University Hospital. BioMed Res Int. 2019;1-9.

30. Macia MD, Rojo-Molinero E, Oliver A. Antimicrobial susceptibility testing in biofilm-growing bactéria. Clin Microbiol Infect. 2014:20(10):981-90.

31. Ciofu O, Tolker-Nielsen T. Tolerance and Resistance of Pseudomonas aeruginosa Biofilms to Antimicrobial Agents-How P. aeruginosa can escape Antibiotics. Front Microbiol. 2019;10:913.

32. Abdalhamid B, Elhadi N, Alabdulqader N, Alsamman K, Aljindan R. Rates of gastrointestinal tract colonization of carbapenem-resistant Enterobacteriaceae and Pseudomonas aeruginosa in hospitals in Saudi Arabia. New Microbes and New Infections. 2016;10:77-83. 